\title{
A New Mathematical Method for Pattern Development
}

\author{
Laura Trautmann ${ }^{1 *}$, Attila Piros ${ }^{1}$ \\ 1 Department of Machine and Product Design, Faculty of Mechanical Engineering, Budapest University of Technology and \\ Economics, H-1111 Budapest, Múegyetem rkp. 3., Hungary \\ * Corresponding author, e-mail: trautmann.laura@gt3.bme.hu
}

Received: 06 June 2018, Accepted: 10 September 2018, Published online: 21 November 2018

\begin{abstract}
The specialty of the patterns is that they are present in many disciplines, even our world is organized by them. The application of a regular structure in the field of product design may also open new possibilities. An automatized pattern can be used in many industries, such as interior design, paper industry, and so on. In this article we can see an example for utilization in electronic industry. The innovation is the pattern applied to the product, which was created with a new mathematical method. The goal was to develop a fully automatized general method. The description of the Generalized Design Pattern Vector (GDPV) which contains the functions of geometric transformations is also included.
\end{abstract}

Keywords

pattern design, algorithm design, parameter transformation

\section{Introduction}

Although motivations and experiences of people may differ from each other, nevertheless a given product, a form, or a pattern in its physical form of appearance has a similar effect on them. In general, a pattern is a regular structure that usually consists of replication of simple elements or their mathematically descripted modifications. In many fields, such as aircraft industry, automotive industry, or other technical areas, patterns can improve some special technical properties for instance stiffness as a support structure, however this article is dealing with only the aesthetic aspect of the pattern, since both sides support the quality of product, that is a key factor in the product life cycle.

Forms and colours make up the visual aspect of information and play a vital role in processing it properly. During the course of seeing, information gets into our nervous system, and, besides emotions, they also develop their effects on our body. Forms and colours may have different effects on us, but certain given attributes may be connected to them. Measuring emotions is a complex task, since not only a number of factors are influencing our opinions, but also actually extracting these opinions requires notable proficiency and proper methods.

In long term, the goal is to find out how the shape or the pattern created by the designer impresses the users. It would be a new approach to the design process if we could manipulate the surface consciously, knowing what kind of reactions it will cause in consumers. With this approach we expect higher consumer satisfaction, because it is possible to reach a unique appearance of products and also personalize them according to given preferences of potential users.

The research specifically deals with patterns on consumer products, so in addition to psychological and to sociological studies, it is also necessary to learn the theory of pattern design, to examine the art history and mathematical background of that. This paper shows the results of this literature research, and besides that, it is presenting a new and surprising method for the pattern creation process.

\section{Development from the Design Point of View \\ "Less is more." "Ornaments are crime."}

In the $20^{\text {th }}$ century these two phrases became famous, when modernism meant to be the leading direction. In the $21^{\text {st }}$ century, however, contrary to these, designers have started to create decorations again, and in many cases aesthetics is raised above functionality.

The work of the designers is characterized by a more plastic approach, so the shape of the buildings can be water drops, cucumbers, or clouds, and furniture designers and industrial designers are creating many times works of art rather than functional objects. The start of the new millennium has brought hope, excitement and fear to people, which has greatly contributed to the change in the design world [1]. 
The idea of self-expression replaced the norm that no one should stand out from the crowd [1]. Nowadays people are buying products and tools with which they can show their value system to others and express themselves. As Donald Norman [2] said, one of the most important components of good design is the Reflective Design, which allows the user to show what he is. In addition to functionality, the designer should focus on the conceptual content of the product, moreover, this aspect has become the most important in the last years. The design work thus widened, since the designer should pay attention not only to a matter of form and function, but he also needs to know the cultures and the human behaviour of the environments he intended the product for.

At the same time, technological advancement helps the designers' work. Most importantly, additive manufacturing is what has opened great perspectives. During the manufacturing process, a solid is built layer to layer based on a virtual model. The technology has a great deal of advantages, including the support of communication, product demonstration, optimization, and testing.

It can be seen that design developed greatly, but the methodology of design has not reached up for this development, so this improvement is indispensable in the future.

\section{Relation between Social Psychology, Nature, Mathematics, and Visual Arts}

The term ornamentation - mentioned above - "is derived from the Latin ornament, which means a piece of decoration" [3]. In addition to being generally a geometric form, decoration, or form composed of repetitive elements, such a pattern can function as a communication tool as well. Researchers have repeatedly referred to the ornamentation being able to carry a symbolic message [4]. Ornamentation can also determine globalization trends, as it may include symbols, artistic, cultural, religious and historical elements alike [5].

One of the most influential writings dealing with ornaments was Owen Jones's Grammar of Ornament [6]. He presents examples of decorative arts of different cultures (Egyptian, Persian, Greek, etc.). In addition to describing detailed features, he also reviews developmental processes and the interacting design methods [6]. At the end of his book, he presents examples in order to prove that the base of all natural forms is some kind of geometric shape. In addition to this Jones had another goal with this book:

"I have ventured to hope that, in thus bringing into immediate juxtaposition the many forms of beauty which every style of ornament presents, I might aid in arresting that unfortunate tendency of our time to be content with copying, ..." [6]

Similarities between natural forms and art rules were not only described by Jones [6]. Amongst others, the naturalist Ernst Haeckel [7] examined natural images and showed that microorganisms are positioned in aesthetic shapes (Fig. 1). These life processes are so similar to the drafts used in art rehearsals (symmetry, spiral, etc.) that we may call the "art of creation" that can be found in nature and in the human mind alike [8].

It is proven that at atomic level everything displays regular geometric patterns. However, we cannot describe everything with simple geometries, the phenomena and the complexity of the world cannot be interpreted in this way.

The American painter Jackson Pollock created his paintings with a unique method. He placed the canvas on the floor, then painted it with drip technique in several layers [9]. Extraordinary works were created (an example is shown in Fig. 2), and so Pollock became one of the most prominent figures of abstract expressionist painting. Lots of people tried to imitate his creations but no one has been able to return the charm of Pollock's works.

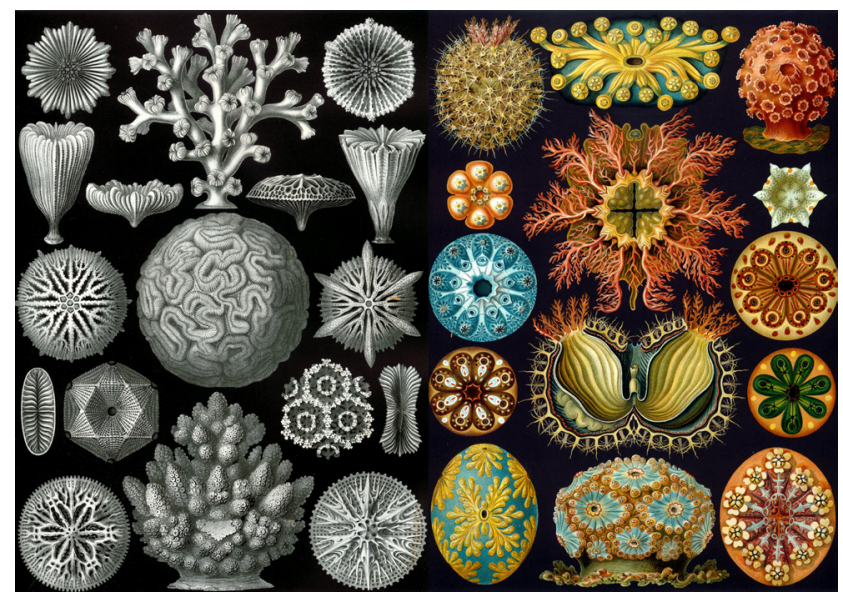

Fig. 1 Examples for microorganisms [7]

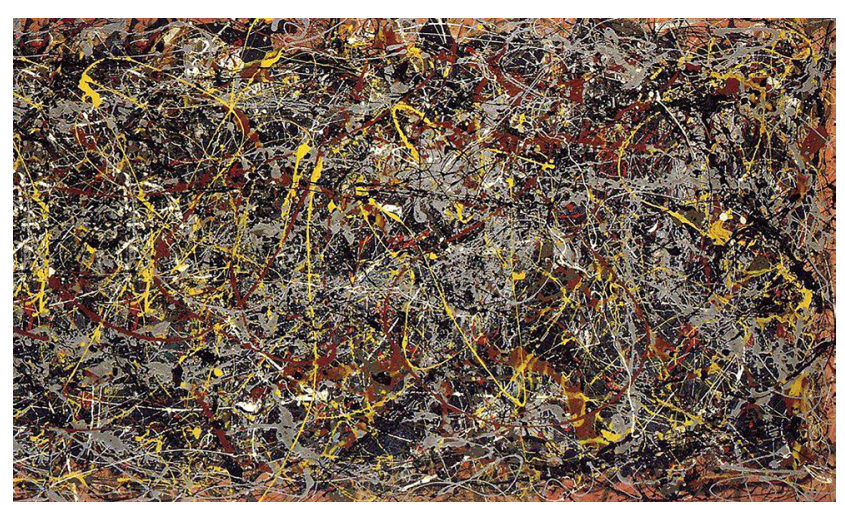

Fig. 2 Number 5 by Jackson Pollock (1948) [10] 
For a long time, nobody knew what made Pollock's pictures so appealing, until Richard Taylor [11], a painter and physicist, discovered in those the self-similar forms [11, 12]. These shapes were named fractals by Benoît Mandelbrot [13], who derived this name from the Latin word "fractus", which means "broken".

The fractals, belonging to the concept set of chaos theory, are patterns that are repeated within themselves at lower organizational levels [11]. Fig. 3 shows one of the first fractals, it is called Koch Snowflake.

However, fractals are not only represented here, but the world is organized on this basis. This form which is based on proportionality can be found everywhere in the nature, from the lace of the leaf of fern to the shape of the clouds through the branching of the lungs of mammalian [14]. This fractal attribution is therefore appealing because the world around us is organized on this basis.

\section{Methods of Pattern-making Processes}

Patterns can't be generated only by the fractal algorithm. The way they are edited may vary, depends on the platform (paper based, pixel- and vector graphic programs, CAD software) we use, but, typically, there are similar theories behind these editions. According to one of the earliest books dealing with the theory of editing [3], the pattern creation process by geometric shapes has been categorized into three groups: longitudinally repeating pattern, bounded surface pattern, and pattern in all directions, i.e. borderless pattern. The editing of the longitudinal and the borderless pattern is done similarly. First

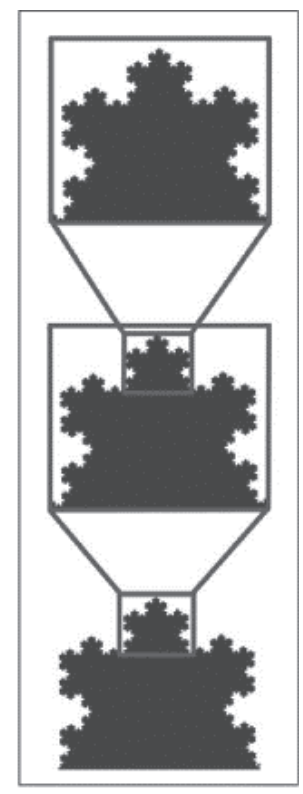

Fig. 3 Koch Snowflake by making a square grid (in the latter case it is possible to use a grid made of triangles as well), then linking the intersection points of these squares based on a same rule with a line, circles, curves, etc. The bordered surfaced geometric pattern is usually placed on pads, ceilings, walls, furniture. The bounded surface is the shape in which the pattern is placed. These are usually simple geometric shapes like rectangle, polygon, circle, ellipse, etc. Here mostly the shape of the surface defines the subject of observation, not the pattern itself, hence the types of geometric patterns are grouped according to the bounded form. For example, based on the equilateral triangle, you can edit the pattern in the following ways [3] (Fig. 4):

1. Patterns may be symmetrically arranged around the bisectrix lines of the triangle. (The bisectrix line divides the angle into two equal angles.)

2. The section of the bisectrix lines of the triangle is the centre of the triangle, which can be also decorated.

3. The peaks of the triangle can also be cut to form the pattern.

4. You may create a new shape by placing different or equal sized triangles on each other. The latter can be a regular hexagon.

Elsewhere also square networks are used as starting points (Fig. 5).

There were mainly two problems with the methods that we have recognised so far. On one hand, the process

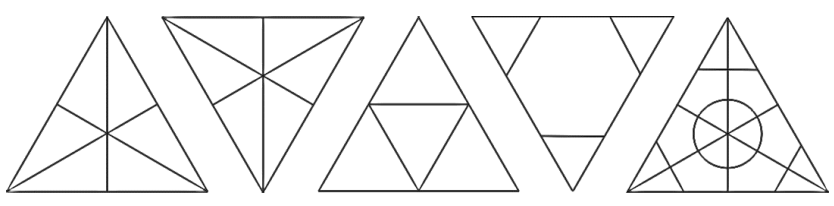

Fig. 4 An example of a equilateral triangle [3]

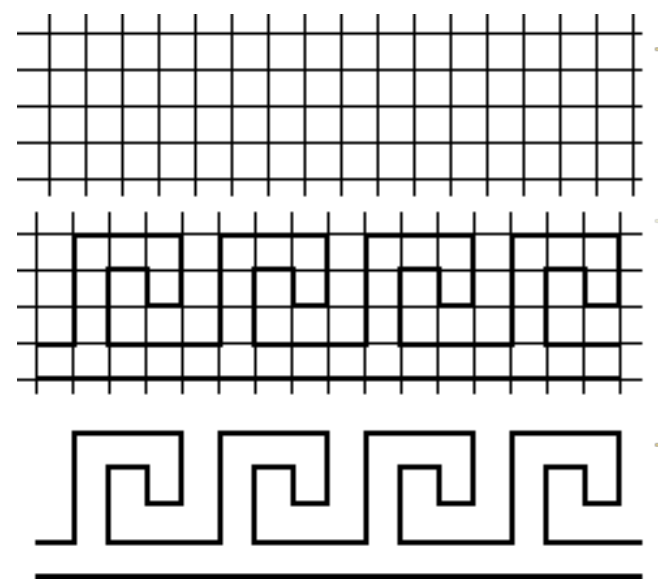

Fig. 5 Simplified "Running Dog" [15] 
in most cases is hard to automatize, on the other hand, the human factor has too much influence, i.e. the process remains subjective. The goal is to create a fully automatized general method. In the next sections a new solution for the pattern creation process will be presented.

\section{Mathematical Approach of Pattern}

\section{Generation Process}

First of all, is it necessary to introduce the new automatized general method with definitions and mathematical operations. In this section it is shown in algebra and graph representation.

- Algebra representation:

Def.: The geometric form $G$ is given by in 2D space

$$
G=\left\{\left(x_{1}, y_{1} ; x_{2}, y_{2} ; \ldots, x_{n}, y_{n}\right) \in R\right\} C R^{n} .
$$

Shortened notation:

$$
G=\left\{\underline{x}, \underline{y} \in R^{n}\right\} \text {. }
$$

Def.: Colour vector

$$
\underline{c} \in C^{3}, \text { where } C=\{0,1,2, \ldots, 255\}
$$

$\underline{c}$ is the RGB triplet of a colour.

Def.: The basic shape $S$ is given by the pair

$$
S=(G, \underline{c}),
$$

where $\underline{c}$ is the colour of each point in $G$.

Def.: The universe of shapes $U$ is given by

$$
U=\{(G, \underline{c})\},
$$

where $G$ is a geometric form, and $\underline{c}$ is it's colour. The geometric transformation can be viewed as operations over the set $U$. For example, the translation by vector

$$
\begin{aligned}
& \underline{t}=\left(t_{1}, t_{2}, \ldots, t_{n}\right) \text { is } T^{(\underline{t})}: U \rightarrow U \\
& T^{(\underline{t})}((G, \underline{c}))=\left(G^{\prime}, \underline{c}\right) \in U, \\
& \text { where } G^{\prime}=\left\{(\underline{x}+\underline{t}) \in R^{n}: \underline{x} \in G\right\} .
\end{aligned}
$$

- Graph representation:

Where the nodes are the basic shapes, and the edges of the graph are the operations.

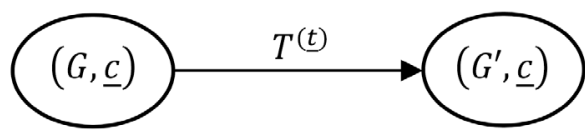

Fig. 6 Graph representation

\section{A new holistic Method for an Automated Pattern Generation Process}

This method consists of mathematical descriptions and operations with the goal of presenting a new way of pattern design. In order to ease comprehension an example is also presented in this section.

The five main steps of the method are illustrated in Fig. 7.

The subsections show these steps in detail.

\subsection{Choosing the Basic Geometry}

The pattern will be composed of a chosen geometry, in this example a teardrop (Fig. 8).

\subsection{Defining a Design Space and the Basic Shape}

First of all, we should define the dimensions. A spatial geometry is determined by three coordinates, which are interpreted in three dimensions. Basically, one dimension can be defined by a parameter and by specifying the measure of this parameter it is clearly possible to characterize the position within the dimension. This way, the temperature may be a dimension, alike any product attribute as colour or surface roughness.

In the case of patterns, the selected dimensions will have at least one geometric dimension, so it is necessary to choose a coordinate system. We may choose a coordinate system in an arbitrary way because of the goal to simplify the pattern development process. Defining a coordinate system is a difficult task, nevertheless the result of this is that the next steps are very easy to automate. In the example a Cartesian coordinate system was chosen.

Naturally the axes of the coordinate system determine

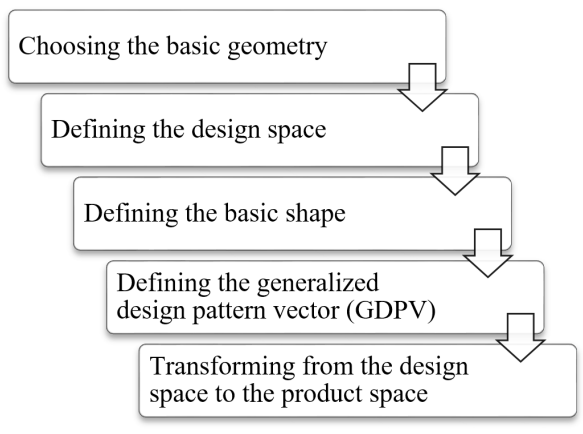

Fig. 7 Main steps of the new method

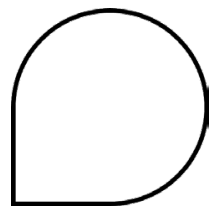

Fig. 8 Choice of base geometry - teardrop shape 
the dimensions, however during the design process we should think in an "n" dimensional space. In this example two geometric dimensions and one colour dimension (RGB(000) - black) were chosen.

Basic shape is the basic geometry and the additional properties together.

\subsection{Defining the Generalized Design Pattern Vector (GDPV)}

The phrases in the title above (generalized, design, pattern, vector) had been linked partially in the literature, for example design pattern vector is used in the field of soft computing for shape recognition in manufacturing system [16]. Moreover, it is also applied in machine learning for maintenance of software systems [17].

There are few disciplines where generalized pattern vector is appeared, among other it is used for design of logic circuits with neural networks [18], and for classify human standing stability [19] as well. However, in the design field it is unique.

The elements of the generalized design pattern vector (GDPV) are the functions of the transformation steps, indicating that how element $n+1$ " is derived from the " $n$ " element. The vectors have the same directions like the directions of the coordinate axes.

In this subsection it is useful to clarify the definitions of two dimensional transformations, because these will be described by functions.

The following list is not comprehensive, only relevant transformations are reviewed.

- Translation (parallel translation) (Fig. 9)

$$
\overrightarrow{P P^{\prime}}=\overrightarrow{Q Q^{\prime}}=t \text {. }
$$

Translation is defined by a vector, composed of the direction and longitude of the translation.

- Rotation (rotation around a point) (Fig. 10)

$$
P O P^{\prime} \angle=Q O Q^{\prime} \angle \text {. }
$$

Rotation is defined by a centre and both the direction and the degree of rotation.

- Reflection on a straight line (Axial reflection) (Fig. 11)

$$
\overrightarrow{P P_{O}}=\overrightarrow{P P^{\prime}}, \quad P P^{\prime} \perp t .
$$

Defined by the axis of reflection (mirror axis).

Fig. 12 summarizes some typical geometric transformations of the Generalized Design Pattern Vector (GDPV). It contains also the parameters necessary for transformation.

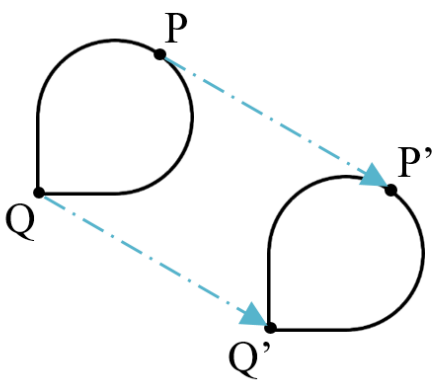

Fig. 9 Translation (parallel translation)

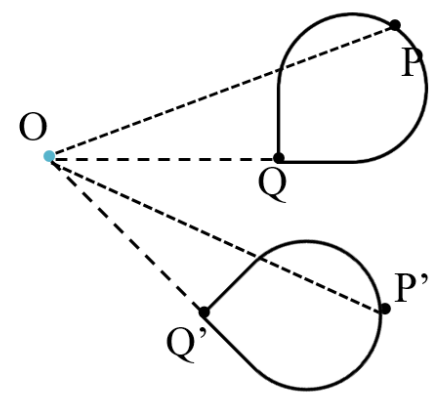

Fig. 10 Rotation (rotation around a point)

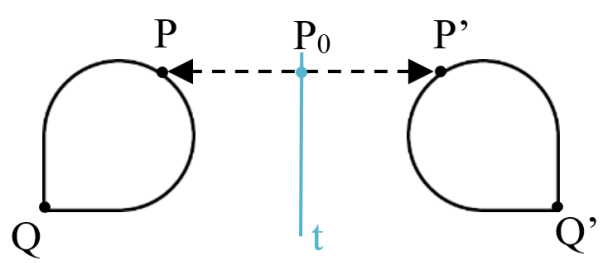

Fig. 11 Reflection on a straight line (Axial reflection)

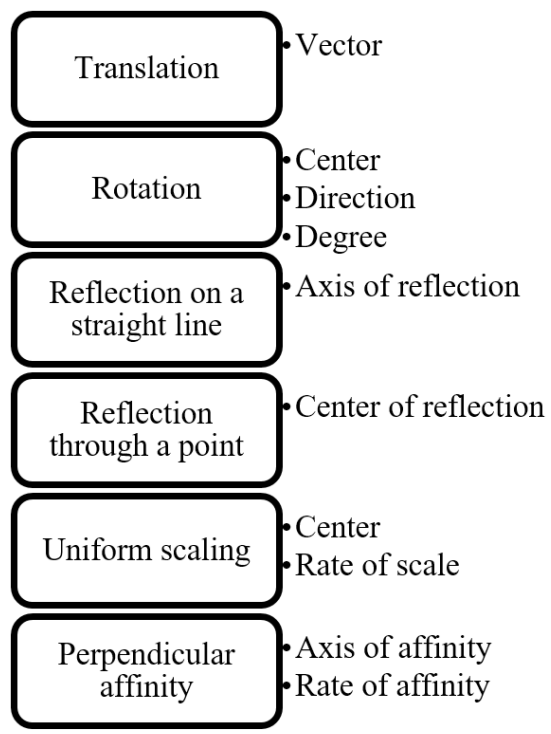

Fig. 12 Typical geometric transformations and the required parameters of the GDPV 
In this example, the $\bar{u}$ and $\bar{v}$ vectors should be defined (Fig. 13). At the $\bar{u}$ vector, numbers different from 0 are appearing only in functions that describing translation and rotation. The translation is defined by a constant value on the $x$ axis $\left(T R_{1}\right)$, the rotation is $90^{\circ}\left(R T_{1}\right)$ in case of every second geometry. (Fig. 14) $T R_{1}$ and $R T_{1}$ are commutative, and $S$ still indicates the basic shape.

In the $\bar{v}$ vector, the reproduction is made by translation on the $y$ axis $\left(T R_{2}\right)$ and a reflection $\left(R F_{1}\right)$ occurred around the vertical centre axis (Fig. 15).

Fig. 16 shows the final pattern.

Fig. 17 presents the process with graph representation according to Fig. 6.

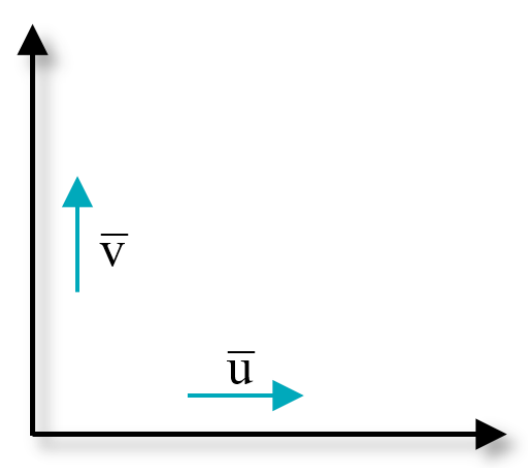

Fig. 13 Vectors to the directions of the coordinate axes

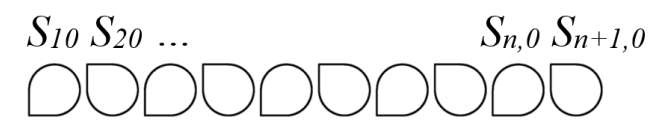

Fig. 14 Definition of $\bar{v}$ vector, created in PTC Creo 4 and Gimp 2 programs

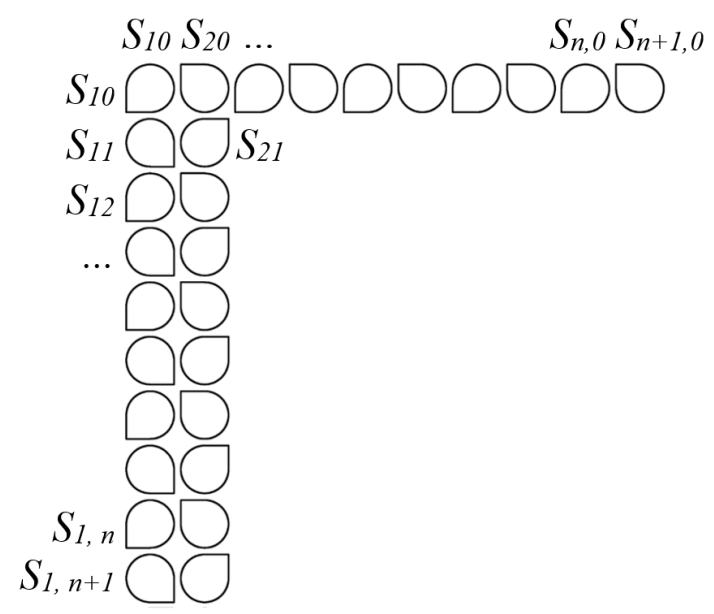

Fig. 15 Definition of $\bar{u}$ vector, created in PTC Creo 4 and Gimp 2 programs

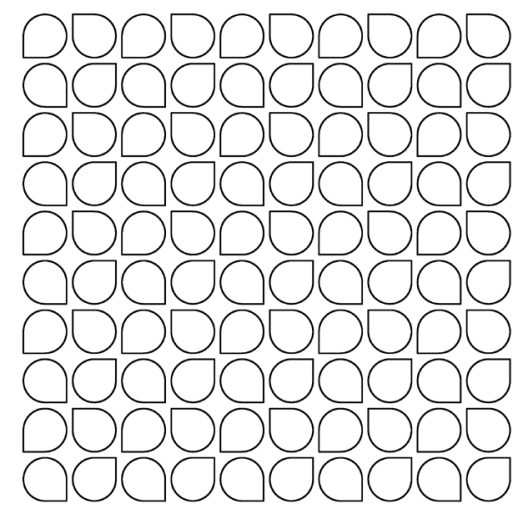

Fig. 16 Final pattern, created in PTC Creo 4 and Gimp 2 programs

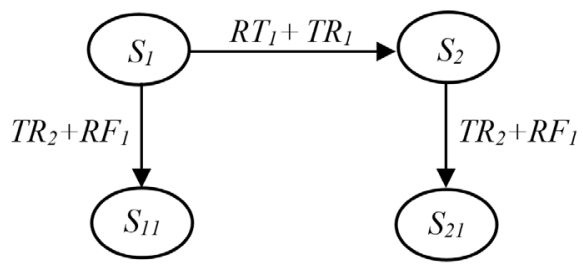

Fig. 17 Graph representation of the example

\subsection{Transforming from the Design Space to the Product Space}

This transformation may vary depending on the chosen dimensions. In the case of geometry, the pattern is applied to the final product by coordinate transformation. However, for example in the case of colours, transformation occurs from colour space to colour space.

The product serving as the example is a new concept for a portable speaker, in which case the pattern was applied on a free-form surface. In such cases, proper projection should be applied (here spherical) which transforms the pattern on the surface.

In this product a multi-level utilization of the basic geometry can be recognised. The teardrop shape defines the body and the buttons of the speaker (Fig. 18).

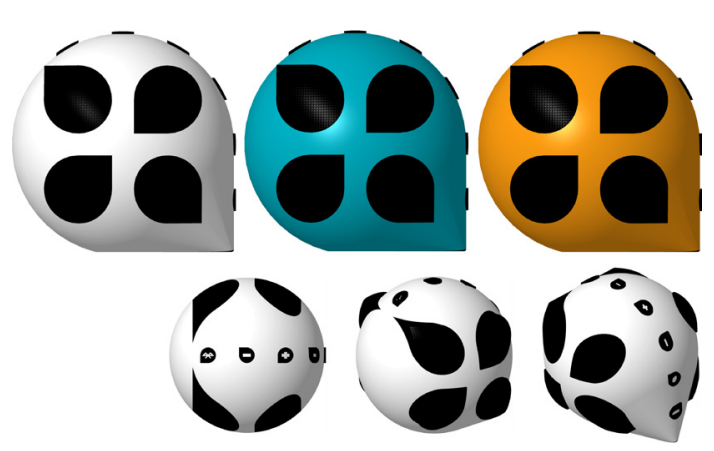

Fig. 18 Product views and colour variations 
The grid holder element is defined by a unit of the pattern, while last but not least the final pattern defines the perforation of the speaker grid (Fig. 19).

\section{Conclusion}

Patterns may be a link between nature, mathematics, visual art, and social psychology. There are mathematical algorithms, patterns made by hand, pictures of microorganisms, and historical meanings of them. Besides these interesting connections, the observation of art history and editorial knowledge of the patterns demonstrated also that the methods used to date are mainly non-automated and the human participation has a great influence. This can be solved by the method presented in this article. The illustrated example is created by only one static solution. However, the aim of the research is to expand it with dynamic (e.g. time-varying) features and to make it visible and programmable.

On the other hand, it is necessary to assess the human emotions. The ultimate idea is that the user provides emotions and then an application transfers the data. The program processes and assigns the specified parameters to the geometries and transformations. (To do this step

\section{References}

[1] Fairs, M. "Design a 21. században" (21st century design), Alexandra Kiadó, Pécs, Hungary, 2007. (in Hungarian)

[2] Norman, D. "Emotional design: why we love (or hate) everyday things", 1st ed., Basic Books, New York, USA, 2005.

[3] Benczúr, B. "A mủvészi ipar és decoratív müvészetek stiltana" (The art industry and decorative arts), Eggenbercer-féle Könyvkereskedés, Budapest, Hungary, 1897. (in Hungarian)

[4] Ladányi-Tóth, M. "Ornamentika a kortárs képzőművészetben" (Ornaments in contemporary fine arts), DLA Dissertation, University of Pécs, 2015. (in Hungarian)

[5] Nadezhda, N. "Ornament as a Symbol of Intercultural Communication", Middle-East Journal of Scientific Research, 17(4), pp. 444-454, 2013. https://doi.org/10.5829/idosi.mejsr.2013.17.04.12158

[6] Jones, O. "The Grammar of Ornament", Bernard Quaritch, London, United Kingdom, 1868.

[7] Haeckel, E. "Art forms in nature", Arina Books, Del Mar, CA, USA, 2011.

[8] Berta, E. Á. "A Goetheanumtól Goethéig" (From Goetheanum to Goethe), Országépítő, 22(1), pp. 35-37, 2011. (in Hungarian)

[9] Zeybek, H., Akyüz, U. "The Influence of Barbizon School's Educational Approach on Modern Art and Nature-Art Relationship in Jackson Pollock Works", EURASIA Journal of Mathematics, Science and Technology Education, 13(11), pp. 7353-7364, 2017.

https://doi.org/10.12973/ejmste/79612

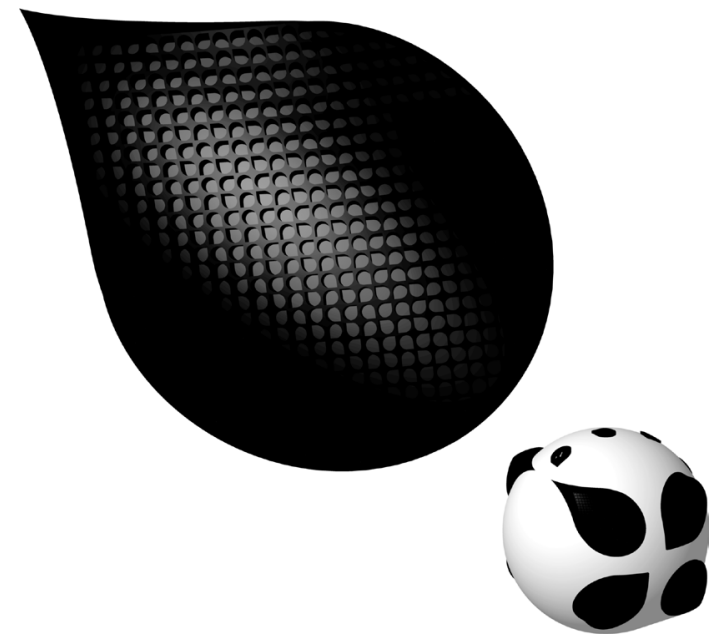

Fig. 19 Using the pattern as a perforation of the speaker grid

emotions must be linked to basic geometries and transformations, to which we will apply fuzzy logics.) The mathematical algorithm generates a pattern that will eventually be placed on a product. To do this, we will need to link a programming software and a 3D design program together. The presentation of these results is expected in the near future.

[10] Anirudh "10 Most famous paintings by Jackson Pollock", 2015, [online] Available at: https://learnodo-newtonic.com/jackson-pollock-famous-paintings [Accessed: 06 December 2017]

[11] Taylor, R. "Personal reflections on Jackson Pollock's fractal paintings", História, Ciências, Saúde-Manguinhos, 13, (Supplement), pp. 109-123, 2006 https://doi.org/10.1590/S0104-59702006000500007

[12] Ouellette, J. "Pollock's Fractals", 2001, [online] Available at: http:// discovermagazine.com/2001/nov/featpollock [Accessed: 05 June 2018]

[13] Mandelbrot, B. "Les Objets Fractals: Forme, Hasard et Dimension" (Fractals : form, chance, and dimension), Flammarion, Paris, France, 1975. (in French)

[14] Perneczky, G. "Képzőművész a matematika és a "szép arányok" tartományai között" (Artist between mathematics and "nice ratios"), Ponticulus Hungaricus, 8(3), 2004. (in Hungarian)

[15] Antal, L. "Geometrikus minták szerkesztése" (Construction of geometric patterns), 2013, [online] Available at: http:/qtp.hu/ mozaik/geometrikus_mintak_szerkesztese.php [Accessed: 06 December 2017] (in Hungarian)

[16] Venugopal, V., Narendran, T. T. "Neural network model for design retrieval in manufacturing systems", Computers in Industry, 20(1), pp. 11-23, 1992.

https://doi.org/10.1016/0166-3615(92)90124-6 
[17] Zanoni, M., Fontana, F. A., Stella, F. "On applying machine learning techniques for design pattern detection", Journal of Systems and Software, 103, pp. 102-117, 2015.

https://doi.org/10.1016/j.jss.2015.01.037

[18] Zdeněk, K., Václav, C. "Learning Processes of Adaptive Threshold Logic Circuits", IFAC Proceedings Volumes, 2(4), pp. 869-873, 1968.

https://doi.org/10.1016/S1474-6670(17)68941-9
[19] Jasinevicius, R., Krušinskienė, R., Satkunskienė, D., Petrauskas, V. "Application of the planar histogram and a set of two single-dimension histograms for human posture disorder classification problem", Journal of Vibroengineering, 11(3), pp. 450-459, 2009. 